\title{
Multiple Expression Assessments of ACE2 and TMPRSS2 SARS-CoV-2 Entry Molecules in the Urinary Tract and Their Associations with Clinical Manifestations of COVID-19
}

This article was published in the following Dove Press journal: Infection and Drug Resistance

\author{
Xiaohan Ren ${ }^{1, *}$ \\ Shangqian Wang ${ }^{1, *}$ \\ Xinglin Chen ${ }^{1} *$ \\ Xiyi Wei ${ }^{1, *}$ \\ Guangyao $\mathrm{Li}^{1, *}$ \\ Shancheng Ren ${ }^{2}$ \\ Tongtong Zhang' \\ Xu Zhang' \\ Zhongwen Lu' \\ Zebing You' \\ Zengjun Wang' \\ Ninghong Song' \\ Chao Qin'
}

'The State Key Laboratory of Reproductive; Department of Urology, The First Affiliated Hospital of Nanjing Medical University, Nanjing 210029, People's Republic of China; ${ }^{2}$ Department of Urology, Shanghai Changhai Hospital, Second Military Medical University, Shanghai, People's Republic of China

*These authors contributed equally to this work
Background: Since December 2019, the novel coronavirus, severe acute respiratory syndrome coronavirus 2 (SARS-CoV-2), first spread quickly in Wuhan, China, then globally. Based on previously published evidence, ACE2 and TMPRSS2 are both pivotal entry molecules that enable cellular infection by SARS-CoV-2. Also, increased expression of proinflammatory cytokines, or a "cytokine storm," is associated with multiple organ dysfunction syndrome often observed in critically ill patients.

Methods: We investigated the expression pattern of ACE2 and TMPRSS2 in major organs in the human body, especially in specific disease conditions. Multiple sequence alignment of ACE2 in different species was used to explain animal susceptibility. Moreover, the cellspecific expression patterns of ACE2 and cytokine receptors in the urinary tract were assessed using single-cell RNA sequencing (scRNA-seq). Additional biological relevance was determined through Gene Set Enrichment Analysis (GSEA) using an ACE2-specific signature.

Results: Our results revealed that ACE2 and TMPRSS2 were highly expressed in genitourinary organs. ACE2 was highly and significantly expressed in the kidney among individuals with chronic kidney diseases or diabetic nephropathy. In single cells, ACE2 was primarily enriched in gametocytes in the testis and renal proximal tubules. The receptors for proinflammatory cytokines, especially IL6ST, were notably concentrated in endothelial cells, macrophages, spermatogonial stem cells in the testis, and renal endothelial cells, which suggested the occurrence of alternative damaging autoimmune mechanisms.

Conclusion: This study provided new insights into the pathogenic mechanisms of SARS$\mathrm{CoV}-2$ that underlie the clinical manifestations observed in the human testis and kidney. These observations might substantially facilitate the development of effective treatments for this rapidly spreading disease.

Keywords: genitourinary organs, pro-inflammatory cytokine receptors, kidney, testis, SARS-CoV-2

\section{Introduction}

With the appearance of SARS-CoV-2 in Wuhan, China, it rapidly evolved to become a complex challenge globally for health authorities to contain the coronavirus disease 2019 (COVID-19) epidemic. On March 11, 2020, COVID-19 was declared a pandemic by the World Health Organization (WHO). ${ }^{1}$ Two previous separate outbreaks of coronaviruses (severe acute respiratory syndrome,

\footnotetext{
Correspondence: Chao Qin; Ninghong Song

The State Key Laboratory of Reproductive; Department of Urology, The First Affiliated Hospital of Nanjing Medical University, Nanjing 210029, People's Republic of China

Tel +86 I3776678978; +86 I565I728807

Email nmuqinchao@163.com;

songninghong_urol@I63.com
}

Infection and Drug Resistance 2020: 13 3977-3990

3977

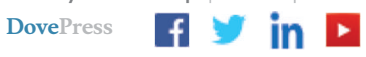

htp: $/ 1$ doi.

(c) (i) (5) 2020 Ren et al. This work is published and licensed by Dove Medical Press Limited. The full terms of this license are available at https://www.dovepress.com/terms.php (c) BY NC and incorporate the Creative Commons Attribution - Non Commercial (unported, v3.0) License (http://creativecommons.org/licenses/by-nc/3.0/). By accessing the work you hereby accept the Terms. Non-commercial uses of the work are permitted without any further permission from Dove Medical Press Limited, provided the work is properly attributed. For permission for commercial use of this work, please see paragraphs 4.2 and 5 of our Terms (https://www.dovepress.com/terms.php). 
SARS-CoV, and Middle East respiratory syndrome, MERS-CoV) emerged in specific regions of the world before the appearance of SARS-CoV-2., ${ }^{2,3}$ SARS-CoV-2 is remarkably similar to SARS-CoV with a $76 \%$ amino acid sequence similarity and the same receptor, angiotensin-converting enzyme 2 (ACE2). Concomitantly, TMPRSS2, the serine protease for virus spike (S) protein priming, also was considered indispensable for cell entry by SARS-CoV-2. Thus, ACE2 and TMPRSS2 are proven key molecules for cell entry by SARS-CoV-2. ${ }^{4}$

The dominant clinical signs of COVID-19 are fever and cough, which resemble common viral pneumonia. However, in seriously affected individuals, acute respiratory distress syndrome (ARDS) is the most severe pulmonary complication triggered by a cytokine storm and results in a high mortality rate. ${ }^{5}$ However, in addition to the primary symptoms that affect the respiratory system, the possibility of COVID-19 damaging the digestive and urogenital tracts has been reported, possibly due to high viral loads and the biological functions of ACE2. ${ }^{6}$ Moreover, the amplified pro-inflammatory cytokines could spill over into the circulation and induce a "cytokine storm," leading to multiple organ dysfunction syndrome in critically ill patients. ${ }^{7}$ Recent studies have reported damage to the urinary tract in patients infected with COVID-19. A retrospective study by Huang et al reported the outcomes of 41 COVID-19 patients in Wuhan and stated that three patients developed complicated acute kidney injury (AKI), and all three required ICU care $^{8}$ Another retrospective, multi-center cohort study demonstrated the epidemiological and clinical characteristics of 191 COVID-19 patients, of whom 27 individuals were reported to have AKI, and ten were treated with continuous renal replacement therapy (CRRT). ${ }^{9}$ A brief review of existing papers that reported urinary system impairment associated with COVID-19 infection is shown in Table $1 .^{8-19}$

Nevertheless, substantial gaps remain in our knowledge of the biology of COVID-19. In this study, we performed an in-depth investigation into the underlying mechanisms of genitourinary system injury caused by COVID-19. We conducted a series of bioinformatics analyses on tissues and single-cells based on the evaluation of multi-access and multiple databases. We hypothesized that in critically ill patients, an inflammatory cytokine storm could directly attack specific cells in the kidney and testis due to their high expression of ACE2 and cytokine receptors, leading to injury of the urinary tract. Our study provides a more detailed and comprehensive perspective of the pathogenesis mechanisms associated with SARSCoV-2 infection of the human testis and kidney.

\section{Methods}

\section{Clinical and Epidemiological Information}

The clinical and epidemiological data for COVID-19 were downloaded from an open-access and continuously updated resource (https://tinyurl.com/s6gsq5y) on April 22, 2020. ${ }^{20}$ The visualization map of known COVID-19 cases, worldwide, was available on the website https://coronavirus.jhu. edu/map.html (John Hopkins University).

\section{Tissue Resources}

The expression values of ACE2 and TMPRSS2 mRNA and protein in normal tissues were obtained from the following databases, Human Protein Atlas (HPA), The Functional Annotation of The Mammalian Genome (FANTOM5), and The Genotype-Tissue Expression (GTEx). Briefly, the HPA database supplied a map of the transcriptome and proteome profiles across 32 tissues and approximately 40 different cell types in the human body. ${ }^{21}$ The FANTOM5 project, an international collaborative effort initiated by RIKEN, collected transcriptome data based on more than three thousand human and mouse samples, including all major organs in the human body and over 200 cancer cell lines. ${ }^{22}$ GTEx provided mRNA expression data from 54 separate normal tissue sites across nearly 1000 individuals. ${ }^{23}$

The mRNA expression data of ACE2 and TMPRSS2 from 33 cancer types and normal counterparts also were obtained in TCGA using the author's R codes. Through the Gene Expression Omnibus (GEO) databases, including major human organs, GSE3526 ${ }^{24}$ and GSE8124 ${ }^{25}$ were chosen to detect ACE2 and TMPRSS2 mRNA expression values. Simultaneously, to explore the different ACE2 and TMPRSS2 expression levels in different people, and using sample counts that were greater than 20, the following genes were selected, GSE113439 (lung tissue; pulmonary arterial hypertension vs control), GSE66494 (kidney tissue; chronic kidney disease vs control), ${ }^{26}$ GSE96804 (kidney tissue; diabetic nephropathy vs control), ${ }^{27}$ and GSE10006 (airway epithelium; smoker vs nonsmoker). ${ }^{28}$ The panel of immunohistochemistry (IHC) images evaluating the protein levels of ACE2 and TMPRSS2 in multiple organs was obtained from the HPA website. 


\section{Multiple Sequence Alignment - ACE2}

The reported ACE2 gene sequences from different species were downloaded from the National Center for Biotechnology Information (NCBI, https://www.ncbi.nlm. nih.gov/), which included humans (Homo sapiens), domestic chickens (Gallus gallus), waterfowl (Tadorna cana), cats (Felis catus), domestic ferrets (Mustela Putorius furo), wild boars (Sus scrofa), dogs (Canis lupus familiar), raccoons (Procyon lotor), masked palm civets (Paguma larvata), tigers (Panthera tigris altaica), domestic cattle (Bos taurus taurus), and raccoon dogs (Nyctereutes procyonoides). Using MEGA X software, we analyzed differences in gene structure and identified molecular markers via sequence alignment. MEGA X, with the kimura-2 parameter (K2P) model, was used to calculate the genetic distance within species and build a Neighbor-Joining (NJ) tree. ${ }^{29}$

\section{Single-Cell RNA Sequencing (RNA-Seq) Analysis}

We used Kidney Interactive Transcriptomics (http://hum phreyslab.com/SingleCell/) to visualize the distribution of ACE2 in each cell cluster of kidney epithelia and entire kidneys. ${ }^{30,31}$ Two adult testis tissues (Adult 1, unfractionated and Adult 2, unfractionated) of GSE124263 were used to visualize the ACE2 expression pattern in testis cell subgroups. ${ }^{32}$ Human Cell Landscape (http://bis.zju.edu.cn/ HCL/index.html) was used to visualize the expression patterns for ACE2 and multiple cytokine receptors (CSF1R, CSF2RA, CSF2RB, FGFR2, IFNGR1, IFNGR2，IL6R, IL6ST, IL7R, IL10RA, IL10RB, IL17RA, and NGFR) in single cells from kidney and testis. ${ }^{33}$

\section{Gene-Set Enrichment Analysis for the ACE2-Specific Signature}

GSEA (version 4.0.3) was performed in specific cells to explore the biological processes associated with ACE2positive cells. The gene set was C5.BP.v7.1.

\section{Results}

\section{Clinical and Epidemiological Features of COVID-19 at Diagnosis}

Table S1 shows the clinical features of 1911 patients infected with SARS-CoV-2. At the onset of infection, the most common symptom was fever (1002 of the 1911 patients, 52.4\%), followed by cough (566 of the 1911 patients, 29.6\%). Also, China had a larger proportion of
COVID-19 patients under 50 years of age compared with patients outside of China. Notably, patients outside of China were typically over 70 years of age. Interestingly, COVID-19 patients in China were more likely to exhibit fever, cough, and fatigue symptoms. COVID-19 epidemiological information is shown visually in Figure S1.

\section{The Expression of ACE2 and TMPRSS2 in Normal Tissues}

In the FANTOM5, HPA, and GTEx databases, ACE2 mRNA and its protein expression were concentrated primarily in the small intestine, testis, kidney, and gallbladder (Figure 1A). The mRNA expression of TMPRSS2 showed a nearly fourfold increase in the prostate, stomach, and small intestine. However, the TMPRSS2 protein expression was highest in the kidney (Figure 1B). The expression of ACE2 and TMPRSS2 mRNAs was high in the testis, kidney, and colon (Figure 1C-D) in GSE3526 and GSE8124. There also was high mRNA expression of ACE2 in the kidney, placenta, bone marrow, and testis, which was confirmed by TCGA. Briefly, the results demonstrated relatively higher expression levels of ACE2 and TMPRSS2 in testis and kidney when the evidence from multiple databases was considered.

ACE2 was stably expressed in multiple tissue samples taken from the central nervous system (CNS), including the cerebellum, amygdala, corpus callosum, and others (Figure 1E). TMPRSS2 also was widely expressed in the CNS (midbrain, subthalamic nucleus, spinal cord, and others) (Figure 1E). Also, IHC results revealed that ACE2 was overexpressed in kidney tubule cells, as well as seminiferous duct cells and Leydig cells in the testis (Figure 2A-B). Elevated levels of staining for TMPRSS2 were observed in kidney tubule cells (Figure 2C). Moderate staining for TMPRSS2 was observed in the glandular cells of the prostate (Figure 2D). The IHC results for ACE2 and TMPRSS2 in other organs are seen in Table S2 (ACE2; seven organs except for kidney and testis: colon, duodenum, gallbladder, heart, rectum, seminal vesicle, and small intestine) and Table S3 (TMPRSS2; 15 organs except for kidney and prostate: colon, duodenum, stomach, small intestine, rectum, thyroid gland, parathyroid gland, lung, salivary gland, liver, gallbladder, pancreas, epididymis, seminal vesicle, and appendix).

\section{ACE2 and TMPRSS2 Expression Patterns in Specific Patient Populations}

Compared with the control group, patients with pulmonary arterial hypertension, chronic kidney disease, and diabetic 


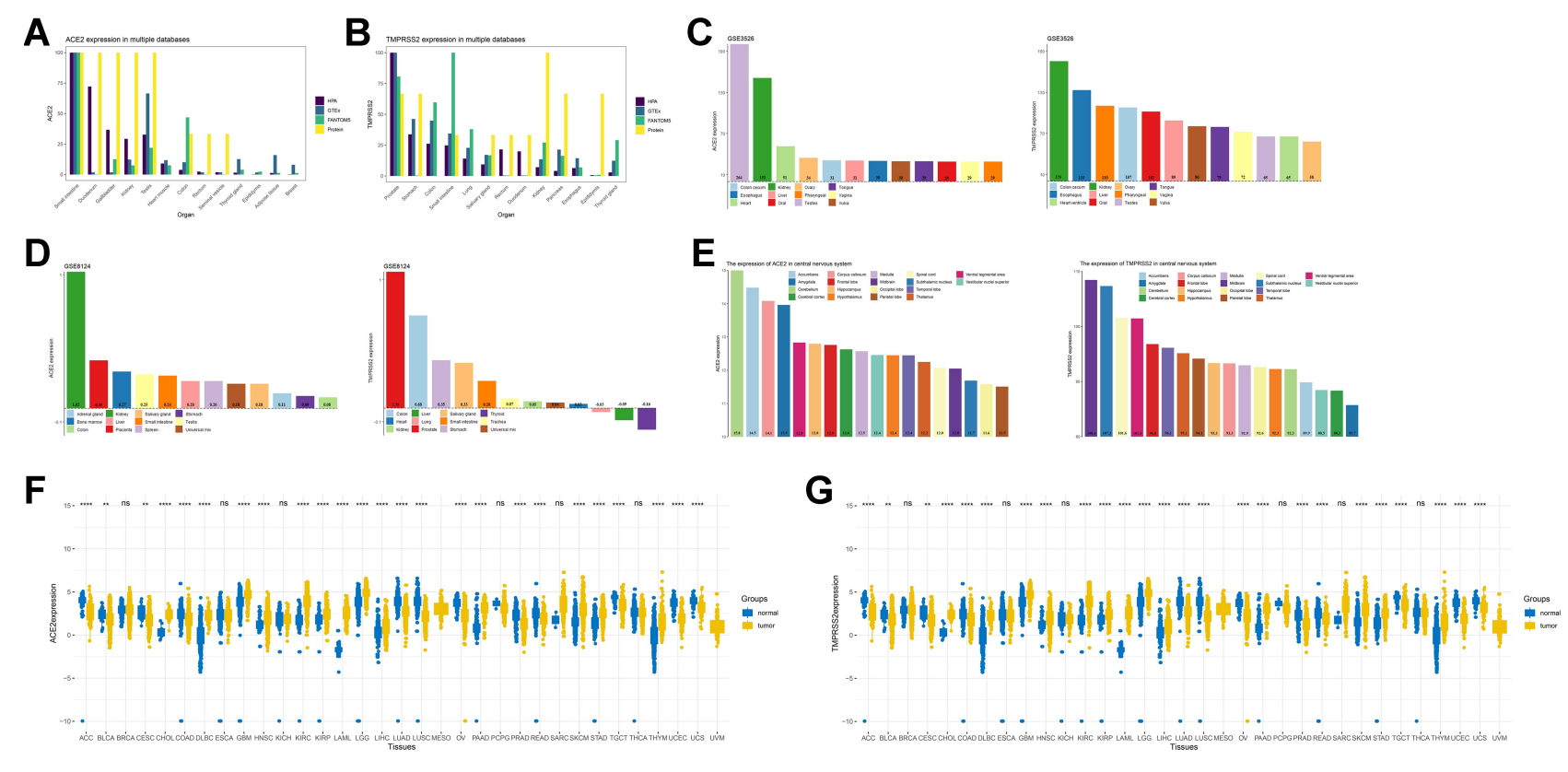

Figure I The expression of ACE2 and TMPRSS2 in tissue.

Notes: (A) The mRNA and protein expression pattern of ACE2 in HPA, GTEx and FANTOM5. (B) The mRNA and protein expression pattern of TMPRSS2 in HPA, GTEx and FANTOM5. (C) The mRNA expression pattern of ACE2 and TMPRSS2 in GSE3526. (D) The mRNA expression pattern of ACE2 and TMPRSS2 in GSE8I24. (E) The mRNA expression pattern of ACE2 and TMPRSS2 in central nervous system. $(\mathbf{F})$ The mRNA expression pattern in TCGA, $* *=P<0.01, * * * *=P<0.000 I, n s=P>0.05 .(\mathbf{G})$ The mRNA expression pattern of TMPRSS2 in TCGA, $* *=P<0.01$, **** $=P<0.0001$, ns $=P>0.05$.

nephropathy, as well as smokers, exhibited higher expression levels of ACE2 in their affected tissues (kidneys or lungs) (Figure 3A-D). Moreover, there was a significant increase in ACE2 in digestive system tumor tissues (stomach and colon) and lungs (Figure 3E-F, Figure 1F-G).

\section{Multiple Sequence Alignment - ACE2}

To explore the possible causes of animal susceptibility to SARS-CoV-2, we performed a multiple species-sequence alignment for ACE2, which is a key molecule in Table 1 the process of COVID-19 infection. The results are presented in Table 2 and Figure 4. It appeared that raccoon dogs (distance $=0.142)$, tigers $($ distance $=0.144)$, dogs $($ distance $=0.144)$, cats $($ distance $=0.146)$, raccoons $($ distance $=0.154)$, domestic ferrets $($ distance $=0.160)$, masked palm civets (distance $=$ 0.164 ), domestic cattle (distance $=0.166$ ), and wild boars (distance $=0.172$ ) have an ACE2 sequence that is similar to humans.

\section{Cell-Specific Expression of ACE2 and Cytokine Receptors in Testis and Kidney}

To determine the cell-specific expression of ACE2, we analyzed transcriptome data from published single-cell RNAsequencing studies to decipher the expression pattern of ACE2 in the testis and kidney. ACE2 was highly enriched in the epithelium of renal proximal tubules in the human kidney (Figure 5A-E). Considering the critical role of cytokines in disease pathogenesis, we established a signature for cytokine receptors that included CSF1R, CSF2RA, CSF2RB, FGFR2, IFNGR1, IFNGR2, IL6R, IL6ST, IL7R, IL10RA, IL10RB, IL17RA, and NGFR. As displayed in Figure 5C-E, IL6ST, IFNGR1, and IFNGR2 were elevated in various human kidney cells, especially in endothelial and fenestrated endothelial cells. In GSE124263 from the testis, ACE2 exhibited significantly higher expression in gametocytes (Figure 6A). Furthermore, from the single-cell RNAsequencing data included in the Human Cell Landscape (Testis; Guo), IL6ST and IFNGR1 expression were notably higher in spermatogonial stem cells, differentiating spermatogonia, Leydig cells, late primary spermatocytes, Sertoli cells, myoid cells, endothelial cells, and macrophages. More than half of the cytokine receptors (IL6ST, IFNGR1, IFNGR2, CSF1R, CSF2RA, IL17RA, IL10RB, and IL10RA) were highly expressed in macrophages (Figure 6B).

\section{The Biological Relevance of the ACE2-Specific Signature}

To speculate on the function of ACE2 in kidney proximal tubules, we generated an ACE2-specific signature from 
A

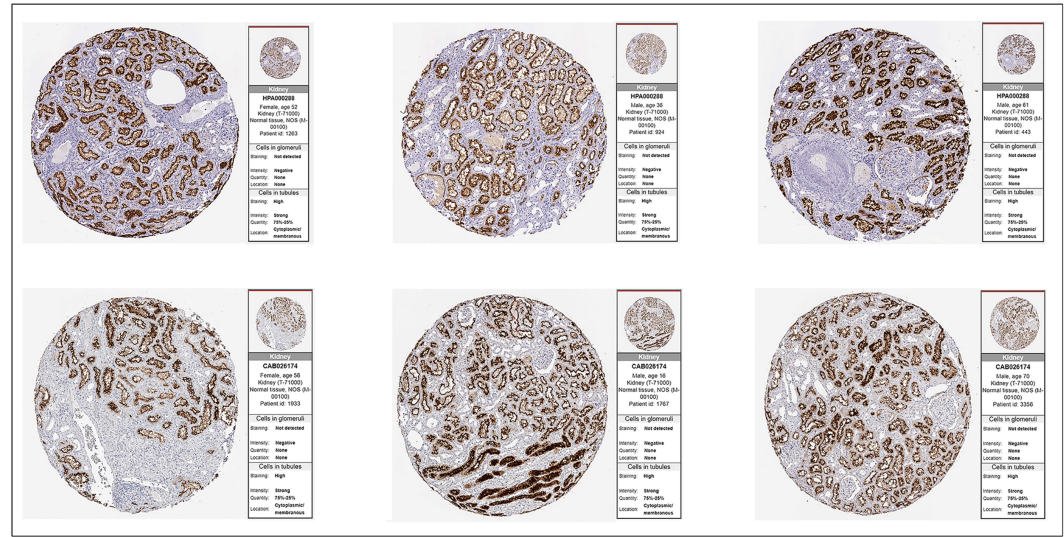

ACE2

\section{Kidney}

B

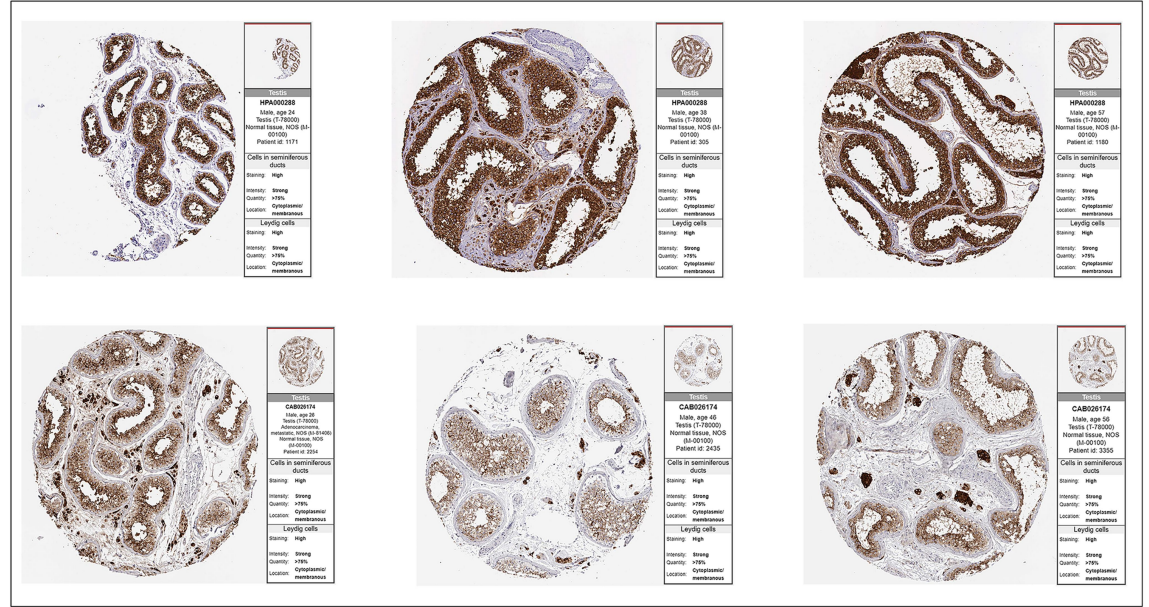

ACE2

Testis

C

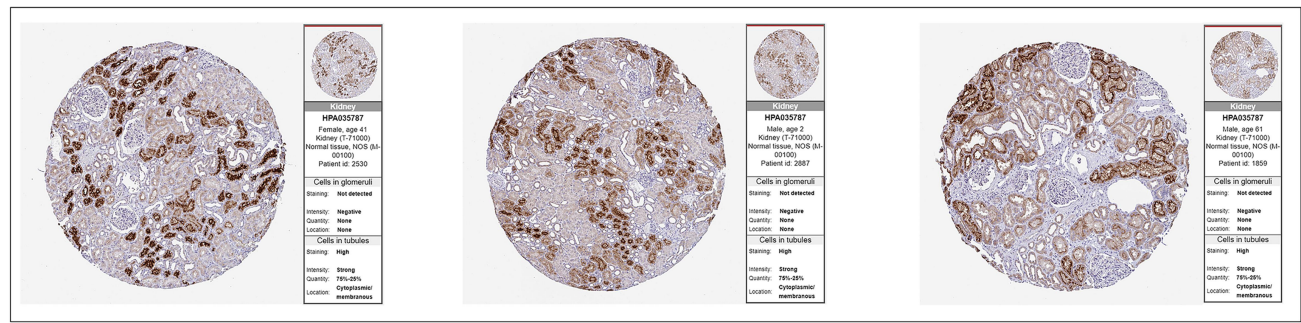

\section{TMPRSS2}

Kidney

D

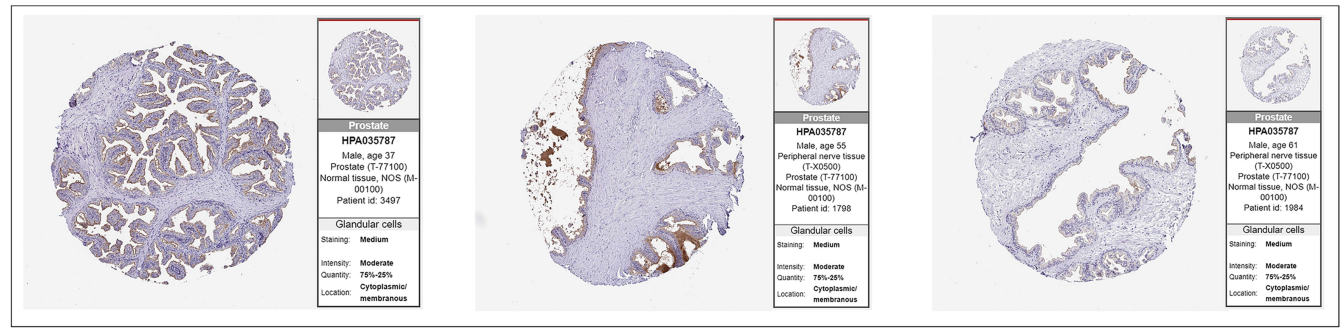

TMPRSS2

Prostate

Figure 2 The panel of immunohistochemical image of ACE2 and TMPRSS2 in target organs.

Notes: (A) The panel of immunohistochemical images of ACE2 in kidney. (B) The panel of immunohistochemical images of ACE2 in testis. (C) The panel of immunohistochemical images of TMPRSS2 in kidney. (D) The panel of immunohistochemical images of TMPRSS2 in prostate. 


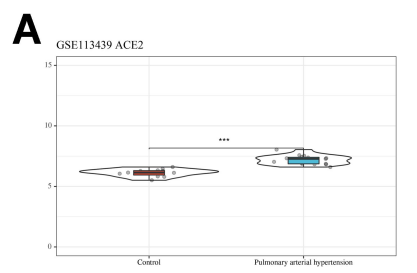

B
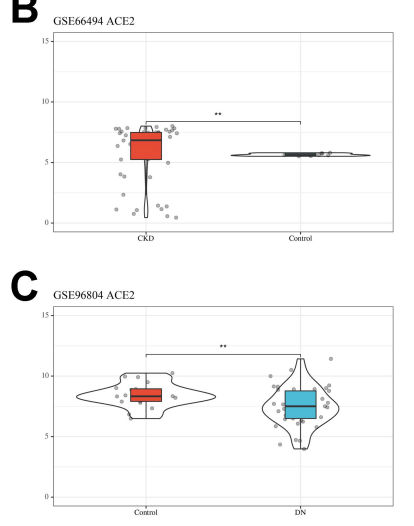

D

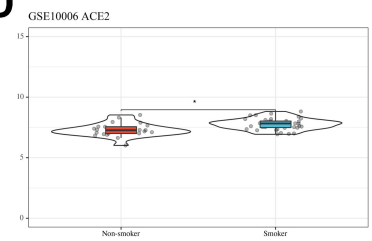

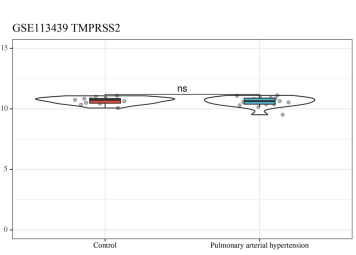
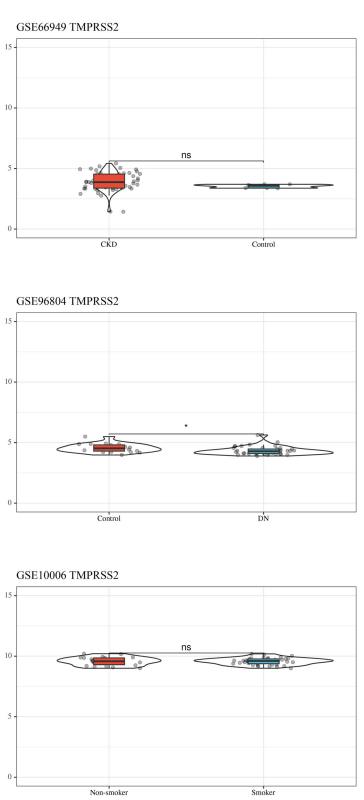

E
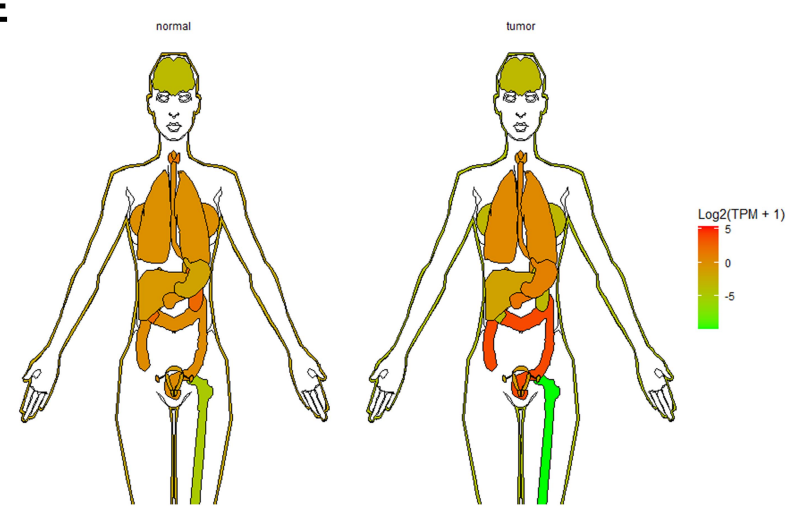

$\mathbf{F}$

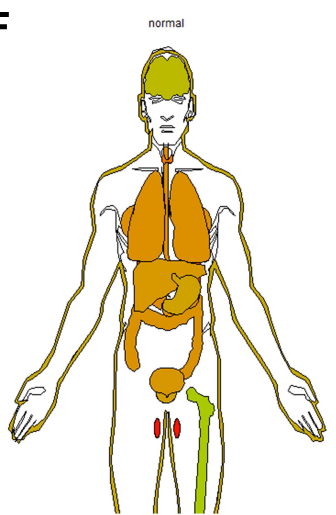

Figure 3 ACE2 and TMPRSS2 expression patterns in specific patient populations. Notes: (A) ACE2 and TMPRSS2 expression patterns in GSEI I 3439, $*=P<0.05, * *=P<0.01, * * *=P<0.001$, ns $=P>0.05$. (B) ACE2 and TMPRSS2 expression patterns in GSE66494, $*=\mathrm{P}<0.05, * *=\mathrm{P}<0.01, * * *=\mathrm{P}<0.00 \mathrm{I}, \mathrm{ns}=\mathrm{P}>0.05$. (C) ACE2 and TMPRSS2 expression patterns in GSE96804, $*=\mathrm{P}<0.05, * *=\mathrm{P}<0.0 \mathrm{I}, * * *=\mathrm{P}<0.00 \mathrm{I}, \mathrm{ns}=$ $\mathrm{P}>0.05$. (D) ACE2 and TMPRSS2 expression patterns in GSEI0006, $*=\mathrm{P}<0.05$, $* *=\mathrm{P}<0.01, * * *=\mathrm{P}<0.001$, ns $=\mathrm{P}>0.05$. (E) ACE2 and TMPRSS2 expression patterns in female. (F) ACE2 and TMPRSS2 expression patterns in male.

ACE2-positive versus negative expression in kidney proximal tubule cells (Figure 7A). The up-regulated functions of ACE2-positive cells were associated with autophagy regulation (GO-bp: regulation of autophagy, negative regulation of autophagy, a process utilizing autophagy mechanisms, and others), immunity (GO-bp: myeloid leukocyte mediated immunity, activation of the innate immune response, and others), virus (GO-bp: viral life cycle, positive regulation of viral genome replication, and others), apoptosis (GO-bp: cellular component disassembly involved in the execution phase of apoptosis), and renal physiology (negative regulation of blood vessel diameter and renal water homeostasis). The down-regulated pathways were associated with immunity (GO-bp: macrophage migration, granulocyte migration, and neutrophil migration).

In the testis, we compared ACE2 expression characteristics in spermatogonial stem cells, Leydig cells, Sertoli cells, and myoid cells (Figure 7B). The up-regulated GO terms in ACE2-positive cells were enriched in cell-cell interactions (GO-bp: regulation of cell-cell adhesion, cell- substrate adhesion, positive regulation of cell-cell adhesion, cell-cell junction organization, and others), virus (GO-bp: regulation of viral genome replication, response to the virus, viral genome replication, and others), and immunity (GO-bp: regulation of leukocyte proliferation, leukocyte proliferation, and others). The down-regulated expression correlated with male reproduction (GO-bp: male meiosis I and male meiotic nuclear division) and response to the virus (GO-bp: cytoplasmic pattern recognition receptor signaling pathway in response to the virus).

\section{Discussion}

With the recent COVID-19 pandemic, it has become apparent that the genitourinary system may be at high risk for injury, which could consequently result in a range of adverse complications. Thus, this study focused on whether SARS-CoV-2 could directly impair genitourinary organs and the manifestations that were observed in target organs, with emphasis on the kidney and testis. 


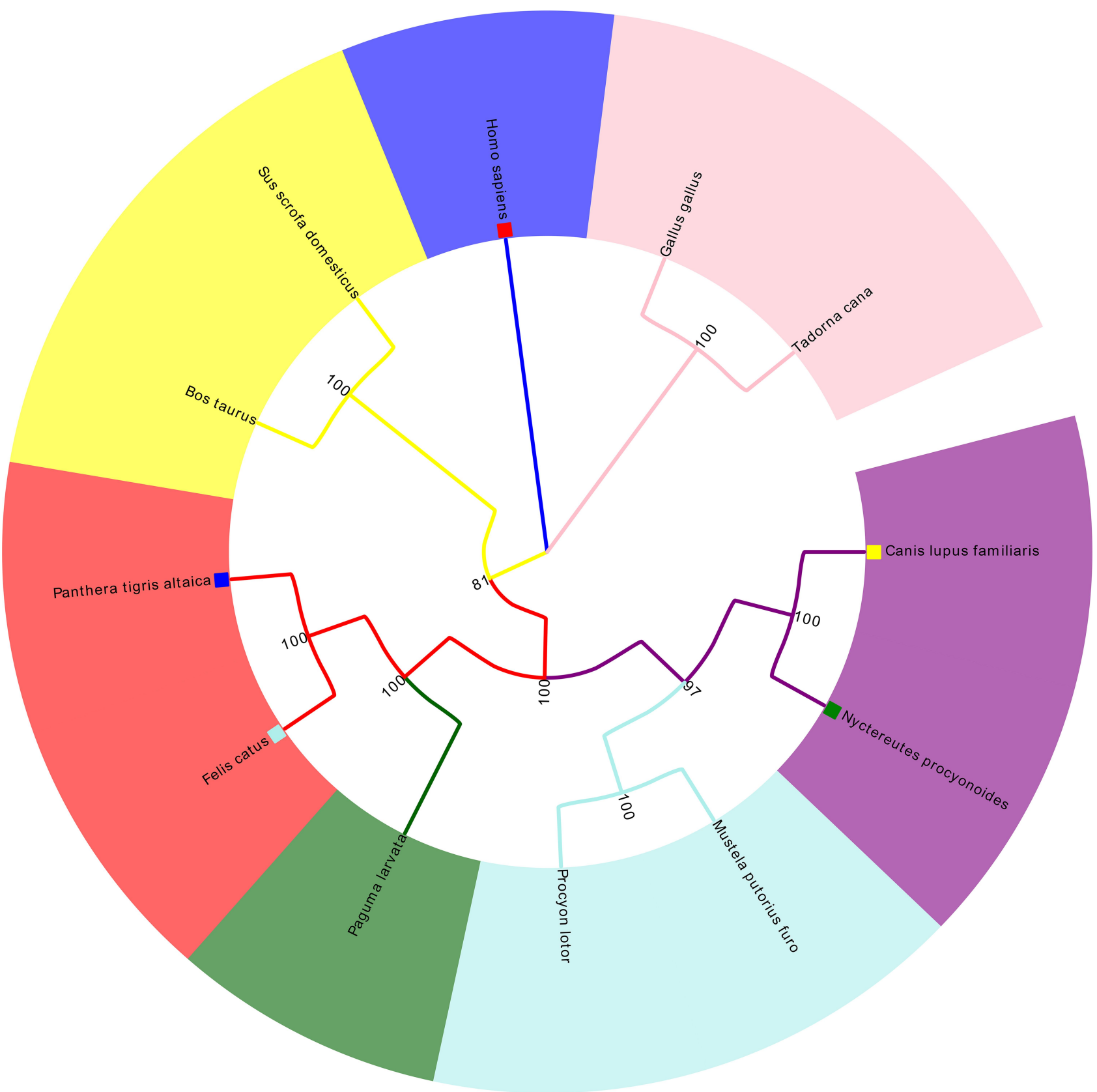

Figure 4 Multiple sequence alignment of ACE2.

Based on the RNA sequence data from normal tissues in multiple databases (HPA, GTEx, FANTOM5, TCGA, and GEO), ACE2 and TMPRSS2 were highly expressed in kidney and testis. Positive SARS-CoV-2 RNA has been found in urine sediments from some severely ill patients with urinary tract-related complications. ${ }^{34}$ It is tempting to speculate that such complications might be mediated by the entry of SARS-CoV-2 into the kidney via ACE2 and TMPRSS2. Up to now, little direct evidence has been demonstrated for injury of the testis by SARS-CoV-2.
However, one study analyzed autopsy specimens of the testis from six patients who died from SARS and reported that the SARS virus could induce orchitis, but no positive ISH staining was detected in the testis. ${ }^{35}$ Another study reported that SARS-CoV-2 transmission through seminal fluid was hard to achieve and that almost no virus RNA was found in testis cells by qRT-PCR. ${ }^{16}$ However, it should be noted that a low detection rate of COVID-19 using PCR was a limitation in these studies. Notably, six of 34 SARS-CoV-2-infected patients (19\%) experienced 
Table I The Brief Review of Existing Paper with Genitourinary System Impairment

\begin{tabular}{|c|c|c|c|c|c|}
\hline \multirow[t]{2}{*}{ Journal } & \multirow[t]{2}{*}{ Author (Year) } & \multicolumn{3}{|l|}{ Cases } & \multirow[t]{2}{*}{ Event } \\
\hline & & Total & Male & Female & \\
\hline Lancet & Huang et al $(2020)^{8}$ & 41 & 30 & II & AKI: 3; CRRT: 3 \\
\hline JAMA & Wang et al $(2020)^{10}$ & 138 & 75 & 63 & AKI: 3; CRRT: 2 \\
\hline Lancet & Zhou et al $(2020)^{9}$ & 191 & 119 & 72 & AKI: 27; CRRT:I0 \\
\hline Intensive Care Medicine & Ruan et al $(2020)^{11}$ & 150 & 102 & 48 & AKI:2I; CRRT: 5 \\
\hline BMJ & Chen et al $(2020)^{12}$ & 274 & $|7|$ & 103 & AKI: 28; CRRT: 3 \\
\hline NEJM & Guan, et al $(2020)^{13}$ & 1099 & 637 & 459 & AKI: 5; CRRT: 9 \\
\hline Intensive Care Med & Tu et al $(2020)^{14}$ & 174 & 79 & 95 & AKI: 19; CRRT: 7 \\
\hline Intensive Care Med & Cao, et al $(2020)^{15}$ & 102 & 53 & 49 & AKI: 8; CRRT:4 \\
\hline Fertility and Sterility & Pan et al $(2020)^{16}$ & 34 & 34 & 0 & Scrotal discomfort: 19 \\
\hline JAMA & Richardson et al $(2020)^{17}$ & 5700 & 3437 & 2263 & AKI: 523; CRRT: $8 \mathrm{I}$ \\
\hline J Am Soc Nephrol & Pei et al $(2020)^{18}$ & 333 & 182 & 151 & AKI: 35 \\
\hline JAMA Netw Open & $\mathrm{Li}$ et al $(2020)^{19}$ & 38 & 38 & 0 & SARS-CoV-2 positive in semen: 6 \\
\hline
\end{tabular}

Abbreviations: AKI, acute kidney injury; CRRT, continuous renal replacement therapy.

Table 2 The Pairwise Distance of ACE2 in Different Species

\begin{tabular}{|c|c|c|c|c|c|c|c|c|c|c|c|c|}
\hline & $\mathbf{I}$ & 2 & 3 & 4 & 5 & 6 & 7 & 8 & 9 & 10 & II & 12 \\
\hline Homo sapiens & - & & & & & & & & & & & \\
\hline Tadorna cana & 0.434 & & & & & & & & & & & \\
\hline Felis catus & 0.146 & 0.421 & & & & & & & & & & \\
\hline Mustela putorius furo & 0.160 & 0.418 & 0.093 & & & & & & & & & \\
\hline Canis lupus familiar & 0.144 & 0.426 & 0.078 & 0.082 & & & & & & & & \\
\hline Gallus gallus & 0.427 & 0.122 & 0.422 & 0.416 & 0.427 & & & & & & & \\
\hline Sus scrofa & 0.172 & 0.438 & 0.140 & 0.152 & 0.150 & 0.440 & & & & & & \\
\hline Procyon lotor & 0.154 & 0.428 & 0.093 & 0.063 & 0.078 & 0.422 & 0.161 & & & & & \\
\hline Paguma larvata & 0.164 & 0.419 & 0.060 & 0.108 & 0.097 & 0.425 & 0.159 & 0.108 & & & & \\
\hline Panthera tigris altaica & 0.144 & 0.424 & 0.010 & 0.091 & 0.077 & 0.421 & 0.143 & 0.091 & 0.060 & & & \\
\hline Bos taurus & 0.166 & 0.440 & 0.141 & 0.152 & 0.139 & 0.437 & 0.121 & 0.148 & 0.152 & 0.138 & & \\
\hline Nyctereutes procyonoides & 0.142 & 0.423 & 0.075 & 0.079 & 0.009 & 0.424 & 0.150 & 0.077 & 0.094 & 0.075 & 0.138 & - \\
\hline
\end{tabular}

Abbreviations: Homo sapiens, human; Gallus gallus, domestic chicks; Tadorna cana, waterfowl; Felis catus, cats; Mustela Putorius furo, domestic ferrets; Sus scrofa, wild boars; Canis lupus familiar, dogs; Procyon lotor, raccoon; Paguma larvata, masked palm civets; Panthera tigris altaica, tigers; Bos taurus taurus, domestic cattle; Nyctereutes procyonoides, raccoon dogs.

scrotal discomfort, which suggested possible testicular damage, although the underlying mechanism was not clear. $^{16}$

Despite the increasing global threat of COVID-19, little is known about the host immune response to SARS-CoV-2 infection. Viral RNA is recognized by the expression of three different cytoplasmic receptors. These receptors are RIG-I-like receptors (RLRs), Toll-like receptors (TLRs), and NOD-like receptors (NLRs). ${ }^{36,37}$ These receptors trigger interferon (IFN) expression and activation of antiviral effectors, including natural killer cells, T CD8+ cells, and macrophages. ${ }^{36,37}$ Zoonotic coronaviruses like SARS-CoV and MERS-CoV have evolved several strategies that suppress IFN production, which could result in exaggerated inflammatory host responses and severe pathological changes in the lungs. ${ }^{38}$ An imbalance in the host immune response and inflammatory cytokines (known as a "cytokine storm"), and chemokine levels, are considered relevant to disease severity and poor prognosis. ${ }^{39,40}$ A study conducted by Winkler et al revealed that infection of SARS-CoV-2 in human ACE2 transgenic mice could result in severe inflammation, immune cell infiltration, and compromised respiratory function. ${ }^{41}$ The immune system also plays a vital role in the disease progression of COVID-19, including decreased levels of multiple immune cells, such as T-lymphocytes, T-helper cells, and natural killer T-lymphocytes, as well as inflammatory cytokines. Compared to patients without hemodialysis, COVID-19 patients undergoing hemodialysis were more likely to experience mild disease and slower progression. $^{42}$ 


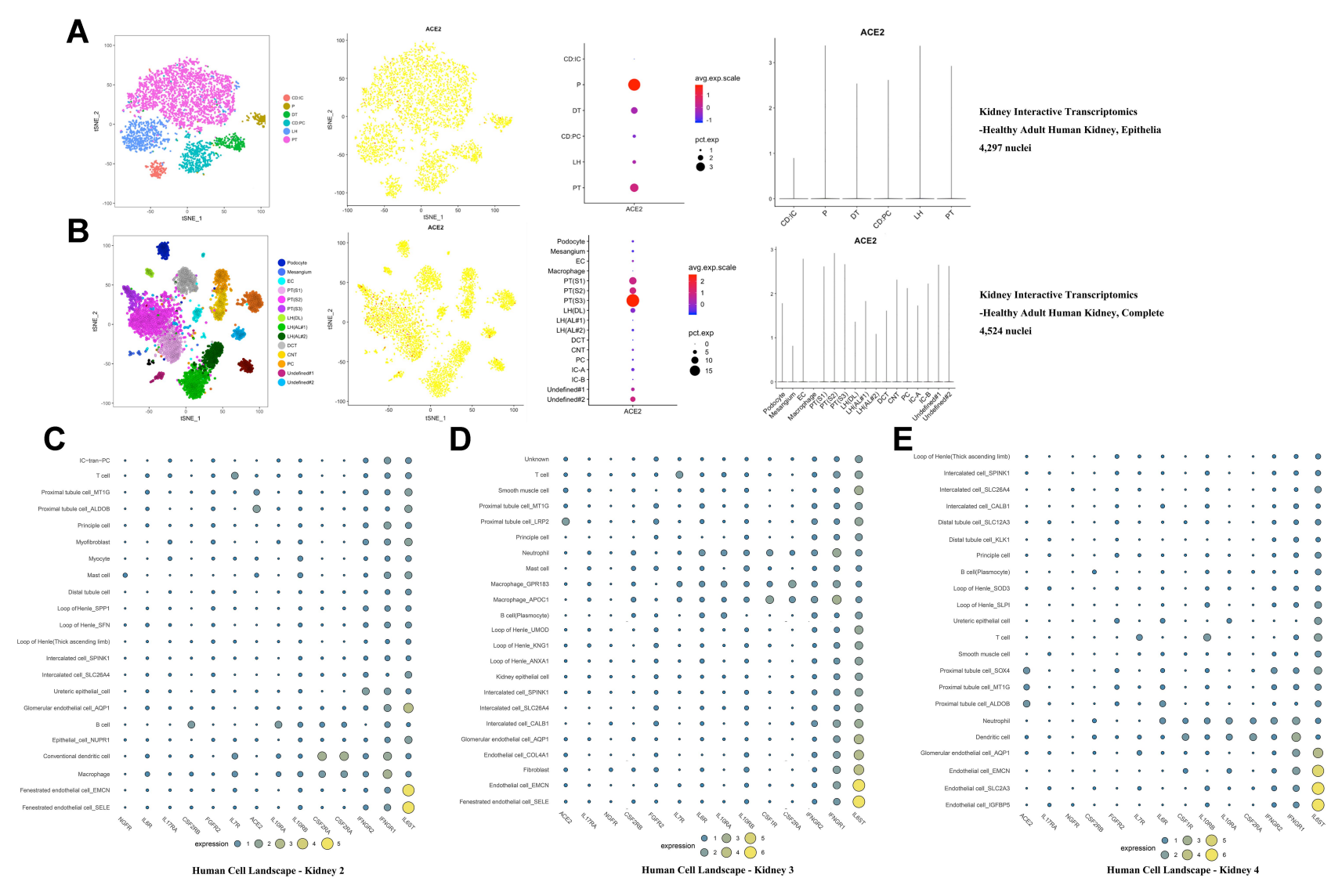

Figure 5 Cell-specific expression of ACE2 and cytokine receptors in kidney.

Notes: (A) Cell-specific expression of ACE2 from http://humphreyslab.com/SingleCell/(Healthy adult human kidney, epithelia). (B) Cell-specific expression of ACE2 from http://humphreyslab.com/SingleCell/(Healthy adult human kidney, complete). (C) Cell-specific expression of ACE2 and cytokine receptors from Human Cell Landscape Kidney2 (http://bis.zju.edu.cn/HCL/search.html). (D) Cell-specific expression of ACE2 and cytokine receptors from Human Cell Landscape Kidney3 (http://bis.zju.edu.cn/ $\mathrm{HCL} /$ search.html). (E) Cell-specific expression of ACE2 and cytokine receptors from Human Cell Landscape Kidney4 (http://bis.zju.edu.cn/HCL/search.html).

Given the possible role of cytokines (especially IL6) in COVID-19 illness, we established a signature that included ACE2 and various cytokine receptors. By performing cellspecific analysis in the kidney using our signature, we found that ACE2 was considerably higher in proximal tubule cells, and IL6ST (the main receptor for IL6) was significantly enriched in fenestrated and glomerular endothelial cells. From the histopathological examinations conducted by $\mathrm{Su}$ et al on 26 autopsy kidney samples from COVID-19 patients, diffuse injury was observed in proximal tubules and included the loss of the brush border, non-isometric vacuolar degeneration, and marked necrosis. ${ }^{43}$ Also, nine samples showed increased serum creatinine and (or) the appearance of proteinuria. Our results might partially explain this phenomenon. First, with higher ACE2 expression in proximal tubule cells, the mutual interaction of ACE2 and SARS-CoV-2 might promote virus entry into the cells. Following cell entry, the virus would cause tissue damage via direct injury due to the viral cytotoxicity. ${ }^{44}$ Kidney proximal tubule cells with ACE2-positive expression showed relevant biological events by GSEA for the mechanisms of injury, including virus regulation, autophagy regulation, and immune and kidney water homeostasis pathways. Second, the elevated cytokines in infected patients could result in aberrant immune responses and local damage via binding with cytokine receptors in fenestrated and glomerular endothelial cells. ${ }^{45}$ This damage would impair the function of the renal glomerular filtration barrier and could feasibly account for the observed abnormalities in serum creatinine and proteinuria.

In the testis, ACE2 is predominantly expressed in gametocytes, Sertoli cells, and spermatogonial stem cells. While this finding suggested that the testis was a high-risk organ that was vulnerable to SARS-CoV-2 infection, direct entry of the virus into the testis would be difficult due to the presence of the blood-testis barrier. One study stated that SARS-CoV -2 was detected in semen. ${ }^{19}$ Also, orchitis was reported as a complication of SARS. ${ }^{35}$ Scrotal discomfort has been reported in COVID-19 patients, indicating potential testis injury. ${ }^{16}$ Based on our results, multiple cytokine receptors were highly expressed in testis macrophages, which may 
A
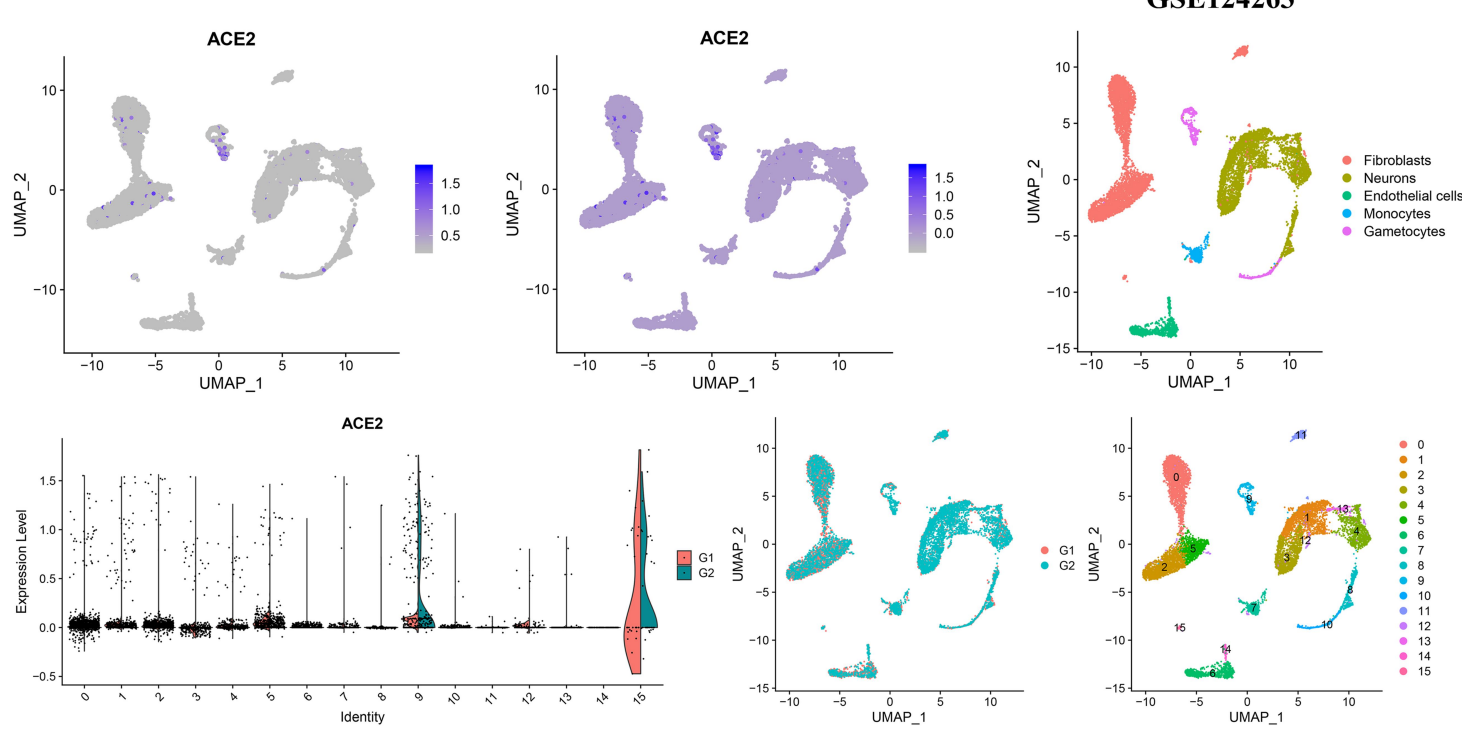

B

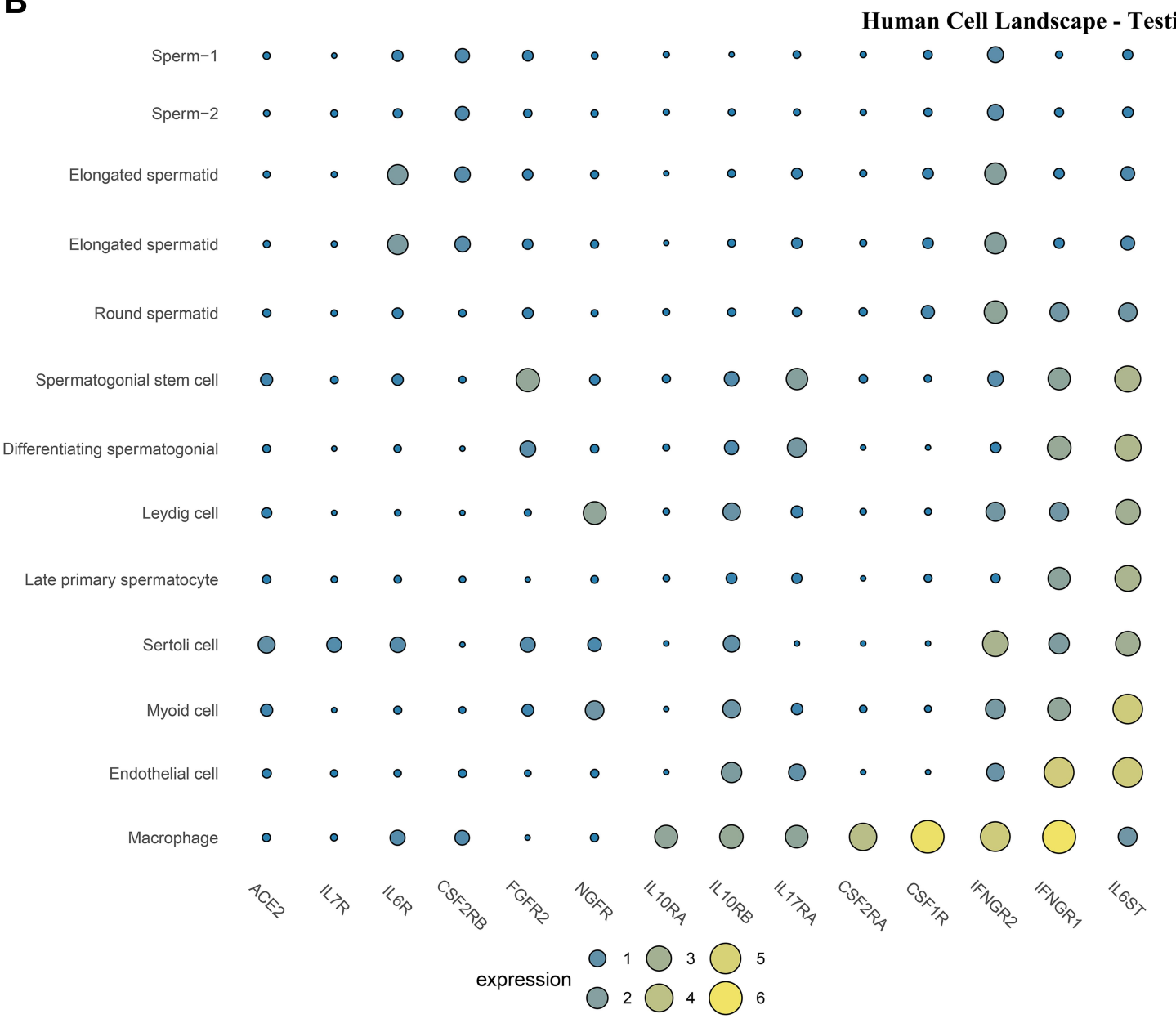

Figure 6 Cell-specific expression of ACE2 and cytokine receptors in testis.

Notes: (A) Cell-specific expression of ACE2 in GSEI24263. (B) Cell-specific expression of ACE2 and cytokine receptors from Human Cell Landscape http://bis.zju.edu.cn/ HCL/search.html. 


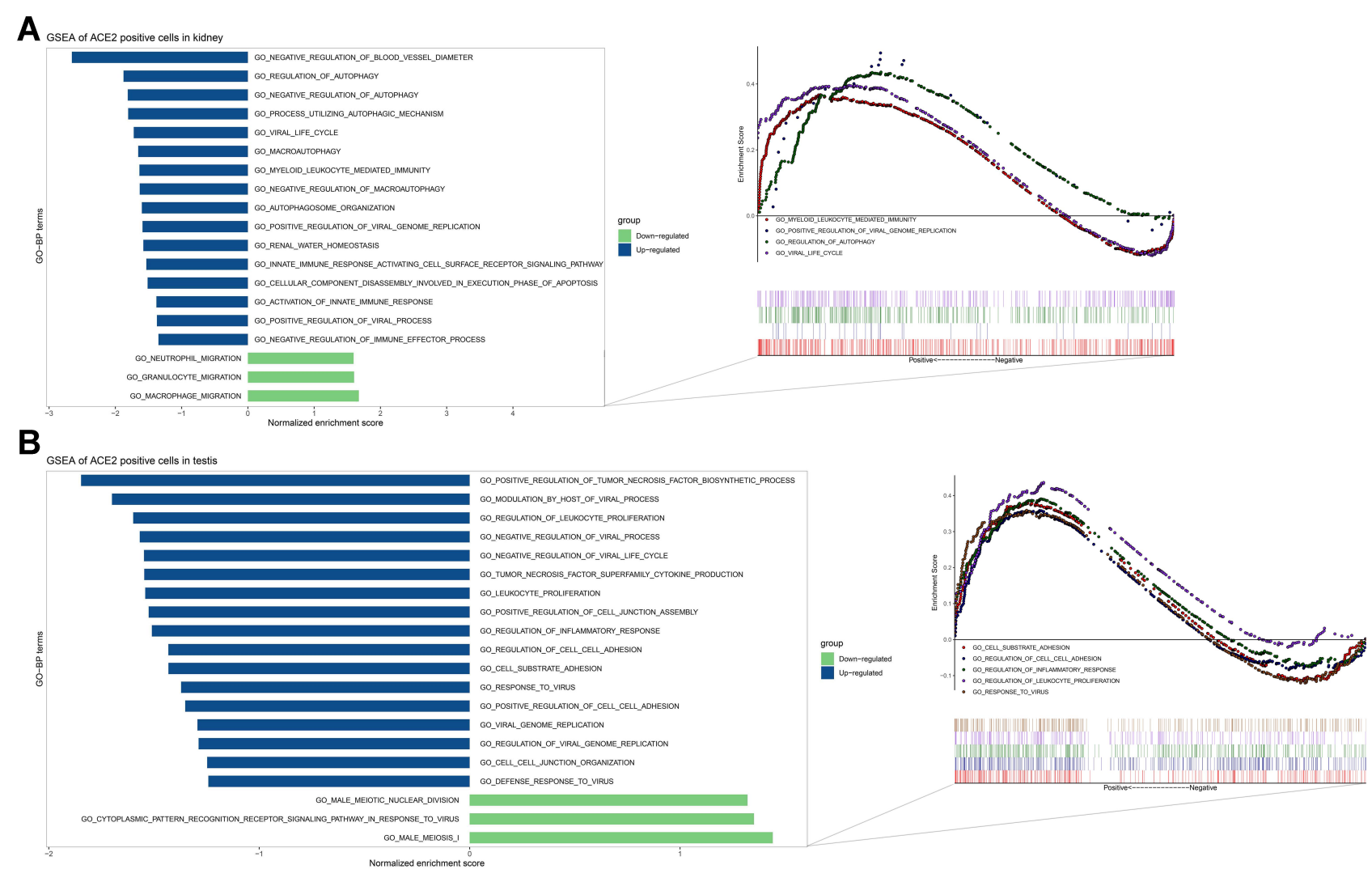

Figure 7 GSEA of ACE2-positive cells in kidney and testis.

Notes: (A) GSEA of ACE2-positive cells in kidney (kidney proximal tubule cells). (B) GSEA of ACE2-positive cells in testis (spermatogonial stem cells, Leydig cells, Sertoli cells, and myoid cells).

disturb their normal functional status, especially in the high cytokine environment of severe COVID-19 patients. An imbalance between macrophages and cytokines is critical in the inflammatory response, which could disrupt Leydig cell function, damage the blood-testis barrier, and directly destroy the seminiferous epithelium. ${ }^{35,46}$ The production of inflammatory factors may activate the autoimmune response and auto-antibody development within the tubules, further triggering a secondary autoimmune response. ${ }^{47}$ Evidence from a rodent model of autoimmune orchitis demonstrated that increased IL6 and its receptor could result in testicular inflammation and germ cell apoptosis, and ultimately, was involved in the pathogenesis of autoimmune orchitis. ${ }^{48}$ Considering the high level of IL6 in severe COVID-19 patients and the enrichment of the IL6 receptor in various testicular cells, this might be a reason for the potential orchitis caused by SARS-CoV-2 infection. As indicated by GSEA, ACE2-positive cells in the testis might express genes implicated in the biological processes of the virus. Although the specific mechanism is not clear, this finding might provide insight into the testicular damage caused by SARS-CoV- 2 .
We believe that cytokines interact with specific cells that highly express cytokine receptors in the kidney and testis, resulting in damage to these target organs. Therefore, for male patients exhibiting severe COVID-19 infections and who are concerned about their fertility, it might be helpful to decrease the level of circulating cytokines using a range of methods, such as hemodialysis, IL-6 antagonists, chloroquine, stem cell therapy, and others. ${ }^{49}$ It is particularly important for COVID-19 patients with varicocele or oligoasthenospermia to decrease cytokine levels to reduce the effects of the viral infection in the testis. Also, AKI was observed in some COVID-19 patients. ${ }^{12}$ In our opinion, therapy such as IL-6 antagonists or others, as mentioned above, could significantly attenuate the kidney injury by inhibiting cytokine expression, thereby improving the prognosis of COVID-19 patients.

Recently, the effects of SARS-CoV-2 on the CNS, and particularly on stroke, have been noticed by researchers. ${ }^{50}$ Downregulation of ACE2 induced by SARS-CoV-2 might activate the classical RAS axis and decrease the alternative RAS signaling in the brain. The resulting imbalance in 
vasodilation, neuroinflammation, oxidative stress, and thrombogenesis could contribute to stroke pathophysiology during SARS-CoV-2 infection. ${ }^{50}$ Our results indicated a broad presence of ACE2 and TMPRSS2 in CNS tissues that are closely associated with stroke, including the cerebellum, ${ }^{51}$ corpus callosum, ${ }^{52}$ hippocampus, ${ }^{53}$ frontal lobe, ${ }^{54}$ cerebral cortex, ${ }^{55}$ and others. Therefore, the tissue tropism of SARS-CoV-2 for ACE2 (or TMPRSS2) and the inflammatory cytokine storm caused by COVID-19 might be an underlying mechanism for stroke. Thus, the risk of stroke in COVID-19 patients should be considered, particularly in patients with prior brain disease or who are elderly.

Some studies have reported animal susceptibility to SARS-CoV-2. ${ }^{56,57}$ Therefore, we conducted an ACE2 sequence alignment in multiple species, which suggested that felidae and canids (cats, tigers, dogs, and raccoon dogs) shared high ACE2 sequence similarity with humans. This might be a possible explanation for the fact that seven tigers in the Bronx zoo (New York, USA) were infected with COVID-19 by an asymptomatic zookeeper infected with COVID-19 (https://www.cnn.com/2020/04/05/us/ tiger-coronavirus-new-york-trnd/index.html). Also, ACE2 is highly expressed in the kidneys among people with chronic kidney diseases and diabetic nephropathy, as well as by airway epithelial cells among smokers and lung tissue among people with pulmonary arterial hypertension. These results suggest that the ACE2 expression increases in the corresponding organs of specific populations with underlying diseases, resulting in a higher risk of infection. Thus, particular attention should be given to related symptoms in these specific populations.

We have noticed an interesting phenomenon in that the proportion of COVID-19 patients under the age of 50 in China is significantly higher than in other countries. Concomitantly, the proportion of COVID-19 patients above the age of 70 in other countries is higher than in China. COVID-19 patients in China are more likely to exhibit symptoms such as fever, cough, and fatigue. The difference in baseline characteristics between the Chinese population and populations outside of China might be a possible reason for these differences. For example, other countries have higher proportions of older individuals. Multiple studies have shown that fever and cough are the most common symptoms of COVID-19 patients in China. ${ }^{13-15}$ However, few studies have assessed the potential differences in symptoms exhibited by COVID-19 patients from Asian and European populations. Our results may provide a novel perspective for differences in clinical performance and therapy in different races. Nevertheless, it also should be noted that this observation was likely to be influenced by selection bias.

In conclusion, based on a range of bioinformatic analyses, this study provided new insights on the impairment of the kidney and testis by SARS-CoV-2 and the possible mechanisms of disease pathogenesis. These findings indicated that the function of the genitourinary system should be carefully assessed in male patients that recover from COVID-19, particularly in patients with fertility concerns.

\section{Acknowledgments}

This work was supported by the Jiangsu Province "Six Talent Peaks Project" (WSN-011), by the National Natural Science Foundation of China (grant number 81672531, 81972386).

\section{Disclosure}

The authors report no conflicts of interest in this work.

\section{References}

1. Ebrahim SH, Ahmed QA, Gozzer E, Schlagenhauf P, Memish ZA. Covid-19 and community mitigation strategies in a pandemic. $B M J$. 2020;368:m1066. doi:10.1136/bmj.m1066

2. Drosten C, Günther S, Preiser W, et al. Identification of a novel coronavirus in patients with severe acute respiratory syndrome. $N$ Engl $\mathrm{J} \mathrm{Med}$. 2003;348(20):1967-1976. doi:10.1056/NEJMoa030747

3. Zaki AM, van Boheemen S, Bestebroer TM, Osterhaus AD, Fouchier RA. Isolation of a novel coronavirus from a man with pneumonia in Saudi Arabia. N Engl J Med. 2012;367:1814-1820. doi:10.1056/NEJMoa1211721

4. Hoffmann M, Kleine-Weber H, Schroeder S, et al. SARS-CoV-2 cell entry depends on ACE2 and TMPRSS2 and is blocked by a clinically proven protease inhibitor. Cell. 2020;181(2):271-280.e278. doi:10. 1016/j.cell.2020.02.052

5. Chen N, Zhou M, Dong X, et al. Epidemiological and clinical characteristics of 99 cases of 2019 novel coronavirus pneumonia in Wuhan, China: a descriptive study. Lancet (London, England). 2020;395:507-513. doi:10.1016/s0140-6736(20)30211-7

6. Wang S, Zhou X, Zhang T, Wang Z. The need for urogenital tract monitoring in COVID-19. Nat Rev Urol. 2020;1-2. doi:10.1038/ s41585-020-0319-7

7. Tisoncik JR, et al. Into the eye of the cytokine storm. Microbiol Mol Biol Rev. 2012;76:16-32. doi:10.1128/mmbr.05015-11

8. Huang C, Wang Y, Li X, et al. Clinical features of patients infected with 2019 novel coronavirus in Wuhan, China. Lancet (London, England). 2020;395:497-506. doi:10.1016/s0140-6736(20)30183-5

9. Zhou F, Yu T, Du R, et al. Clinical course and risk factors for mortality of adult inpatients with COVID-19 in Wuhan, China: a retrospective cohort study. Lancet (London, England). 2020;395:1054-1062. doi:10.1016/s0140-6736(20)30566-3

10. Wang D, Hu B, Hu C, et al. Clinical Characteristics of 138 hospitalized patients with 2019 novel coronavirus-infected pneumonia in Wuhan, China. JAMA. 2020;323:1061-1069. doi:10.1001/jama.2020.1585

11. Ruan Q, Yang K, Wang W, Jiang L, Song J. Clinical predictors of mortality due to COVID-19 based on an analysis of data of 150 patients from Wuhan, China. Intensive Care Med. 2020;1-3. doi:10.1007/s00134-020-05991-x 
12. Chen $\mathrm{T}$, Wu D, Chen $\mathrm{H}$, et al. Clinical characteristics of 113 deceased patients with coronavirus disease 2019: retrospective study. BMJ. 2020;368:m1091. doi:10.1136/bmj.m1091

13. Guan W-J, Ni Z-Y, Hu Y, et al. Clinical characteristics of coronavirus disease 2019 in China. $N$ Engl J Med. 2020;382(18):1708-1720. doi:10.1056/NEJMoa2002032

14. Tu WJ, Cao J, Yu L, Hu X, Liu Q. Clinicolaboratory study of 25 fatal cases of COVID-19 in Wuhan. Intensive Care Med. 2020;1-4. doi:10.1007/s00134-020-06023-4

15. Cao J, et al. Clinical features and short-term outcomes of 18 patients with corona virus disease 2019 in intensive care unit. Intensive Care Med. 2020:1-3. doi:10.1007/s00134-020-05987-7.

16. Pan F, et al. No evidence of SARS-CoV-2 in semen of males recovering from COVID-19. Fertil Sterility. 2020. doi:10.1016/j. fertnstert.2020.04.024

17. Richardson S, Hirsch JS, Narasimhan M, et al. Presenting characteristics, comorbidities, and outcomes among 5700 patients hospitalized with COVID-19 in the New York City Area. JAMA. 2020;323 (20):2052. doi:10.1001/jama.2020.6775

18. Pei G, Zhang Z, Peng J, et al. Renal Involvement and Early Prognosis in Patients with COVID-19 Pneumonia. J Am Soc Nephrol. 2020;31 (6):1157-1165. doi:10.1681/asn.2020030276

19. Li D, Jin M, Bao P, Zhao W, Zhang S. Clinical characteristics and results of semen tests among men with coronavirus disease 2019. JAMA Net Open. 2020;3(5):e208292. doi:10.1001/jamanetworkopen. 2020.8292

20. Xu B, Kraemer MUG, Xu B. Open access epidemiological data from the COVID-19 outbreak. Lancet Infect Dis. 2020;20:534. doi:10.1016/s1473-3099(20)30119-5

21. Uhlén M, Fagerberg L, Hallstrom BM, et al. Proteomics. Tissue-based map of the human proteome. Science. 2015;347 (6220):1260419. doi:10.1126/science.1260419

22. Kawaji H, Kasukawa T, Forrest A, Carninci P, Hayashizaki Y. The FANTOM5 collection, a data series underpinning mammalian transcriptome atlases in diverse cell types. Sci Data. 2017;4:170113. doi:10.1038/sdata.2017.113

23. Carithers LJ, Moore HM. The Genotype-Tissue Expression (GTEx) Project. Biopreservation biobanking. 2015;13:307-308. doi:10.1089/ bio.2015.29031.hmm

24. Roth RB, Hevezi P, Lee J, et al. Gene expression analyses reveal molecular relationships among 20 regions of the human CNS. Neurogenetics. 2006;7(2):67-80. doi:10.1007/s10048-0060032-6

25. Kato M, Miya F, Kanemura Y, et al. Recombination rates of genes expressed in human tissues. Hum Mol Genet. 2008;17(4):577-586. doi: $10.1093 / \mathrm{hmg} / \mathrm{ddm} 332$

26. Nakagawa S, Nishihara K, Miyata H, et al. Molecular markers of tubulointerstitial fibrosis and tubular cell damage in patients with chronic kidney disease. PLoS One. 2015;10(8):e0136994. doi:10. 1371/journal.pone.0136994

27. Shi JS, Qiu DD, Le WB, Wang H, Li S, Lu YH, Jiang S. Identification of transcription regulatory relationships in diabetic nephropathy. Chinese Medical Journal. 2018;131:2886-2890. doi:10. 4103/0366-6999.246063

28. Carolan BJ, Harvey BG, De BP, Vanni H, Crystal RG. Decreased expression of intelectin 1 in the human airway epithelium of smokers compared to nonsmokers. J Immunol. 2008;181:5760-5767. doi:10. 4049/jimmunol.181.8.5760

29. Kumar S, Stecher G, Li M, Knyaz C, Tamura K. MEGA X: molecular evolutionary genetics analysis across computing platforms. Mol Biol Evol. 2018;35:1547-1549. doi:10.1093/molbev/msy096

30. Wu H, Uchimura K, Donnelly EL, et al. Comparative Analysis and Refinement of Human PSC-Derived Kidney Organoid Differentiation with Single-Cell Transcriptomics. Cell Stem Cell. 2018;23:869-881. e868. doi:10.1016/j.stem.2018.10.010
31. Wu H, Malone AF, Donnelly EL, et al. Single-cell transcriptomics of a human kidney allograft biopsy specimen defines a diverse inflammatory response. J Am Soc Nephrol. 2018;29:2069-2080. doi:10.1681/ asn.2018020125

32. Sohni A, et al. The neonatal and adult human testis defined at the single-cell level. Cell Reports. 2019;26:1501-1517.e1504. doi:10.1016/j. celrep.2019.01.045

33. Han X, Zhou Z, Fei L, et al. Construction of a human cell landscape at single-cell level. Nature. 2020;581(7808):303-309. doi:10.1038/ s41586-020-2157-4

34. Wang L, Li X, Chen H, et al. Coronavirus Disease 19 infection does not result in acute kidney injury: an analysis of 116 hospitalized patients from Wuhan, China. Am J Nephrol. 2020:1-6. doi:10.1159/ 000507471.

35. $\mathrm{Xu} \mathrm{J}$, et al. Orchitis: a complication of severe acute respiratory syndrome (SARS). Biol Reprod. 2006;74:410-416. doi:10.1095/ biolreprod.105.044776

36. Nelemans T, Kikkert M. Viral innate immune evasion and the pathogenesis of emerging RNA virus infections. Viruses. 2019;11. doi:10.3390/v11100961.

37. Newton AH, Cardani A, Braciale TJ. The host immune response in respiratory virus infection: balancing virus clearance and immunopathology. Semin Immunopathol. 2016;38:471-482. doi:10. 1007/s00281-016-0558-0

38. Kindler E, Thiel V. SARS-CoV and IFN: too little, too late. Cell Host Microbe. 2016;19(2):139-141. doi:10.1016/j.chom.2016.01.012

39. de Wit E, van Doremalen N, Falzarano D, Munster VJ. SARS and MERS: recent insights into emerging coronaviruses. Nat Rev Microbiol. 2016;14:523-534. doi:10.1038/nrmicro.2016.81

40. Taverna G, Di Francesco S, Borroni EM, et al. The kidney, COVID-19, and the chemokine network: an intriguing trio. Int Urol Nephrol. 2020:1-8. doi:10.1007/s11255-020-02579-8.

41. Winkler ES, et al. SARS-CoV-2 infection in the lungs of human ACE2 transgenic mice causes severe inflammation, immune cell infiltration, and compromised respiratory function. bioRxiv: The Preprint Server for Biology. 2020. doi:10.1101/2020.07.09.19 6188

42. Perico L, Benigni A, Remuzzi G. Reply to the Comment by Dr. Cure on "Should COVID-19 Concern Nephrologists? Why and to What Extent? The emerging impasse of angiotensin blockade". Nephron. 2020;144(5):253-254. doi:10.1159/000507861

43. Su H, Yang M, Wan C, et al. Renal histopathological analysis of 26 postmortem findings of patients with COVID-19 in China. Kidney Int. 2020. doi:10.1016/j.kint.2020.04.003

44. Xu Z, Shi L, Wang Y, et al. Pathological findings of COVID-19 associated with acute respiratory distress syndrome. Lancet Respirat Med. 2020;8(4):420-422. doi:10.1016/s2213-2600(20)30 076-X

45. Zhang Y, et al. A promising anti-cytokine-storm targeted therapy for COVID-19: the artificial-liver blood-purification system. Engineering (Beijing, China). 2020. doi:10.1016/j.eng.2020.03.006

46. Pérez CV, Theas MS, Jacobo PV, et al. Dual role of immune cells in the testis: protective or pathogenic for germ cells? Spermatogenesis. 2013;3(1):e23870. doi:10.4161/spmg.23870

47. Itoh M, Hiramine C, Tokunaga Y, Mukasa A, Hojo K. A new murine model of autoimmune orchitis induced by immunization with viable syngeneic testicular germ cells alone. II. Immunohistochemical findings of fully-developed inflammatory lesion. Autoimmunity. 1991;10: 89-97. doi:10.3109/08916939109004812

48. Rival C, Theas MS, Guazzone VA, Lustig L. Interleukin-6 and IL-6 receptor cell expression in testis of rats with autoimmune orchitis. Journal of Reproductive Immunology. 2006;70(1-2):43-58. doi:10.1016/ j.jri.2005.10.006

49. Ye Q, Wang B, Mao J. The pathogenesis and treatment of the 'Cytokine Storm' in COVID-19. J Infect. 2020;80(6):607-613. doi:10.1016/j.jinf.2020.03.037 
50. Divani AA, Andalib S, Di Napoli M, et al. Coronavirus Disease 2019 and stroke: clinical manifestations and pathophysiological insights. J Stroke Cerebrovasc Dis. 2020;29(8):104941. doi:10.1016/j. jstrokecerebrovasdis.2020.104941

51. Koch G, Bonnì S, Casula EP, et al. Effect of cerebellar stimulation on gait and balance recovery in patients with hemiparetic stroke: a randomized clinical trial. JAMA Neurol. 2019;76(2):170-178. doi:10.1001/jamaneurol.2018.3639

52. Nyffeler T, Vanbellingen T, Kaufmann BC, et al. Theta burst stimulation in neglect after stroke: functional outcome and response variability origins. Brain. 2019;142:992-1008. doi:10.1093/brain/awz029

53. Delattre C, Bournonville C, Auger F, et al. Hippocampal deformations and entorhinal cortex atrophy as an anatomical signature of long-term cognitive impairment: from the MCAO rat model to the stroke patient. Transl Stroke Res. 2018;9(3):294-305. doi:10.1007/ s12975-017-0576-9
54. Shi Y, Zeng Y, Wu L, et al. A study of the brain abnormalities of post-stroke depression in frontal lobe lesion. Sci Rep. 2017;7 (1):13203. doi:10.1038/s41598-017-13681-w

55. Uzdensky A, Demyanenko S, Fedorenko G, Lapteva T, Fedorenko A. protein profile and morphological alterations in penumbra after focal photothrombotic infarction in the rat cerebral cortex. Mol Neurobiol. 2017;54:4172-4188. doi:10.1007/s12035-016-9964-5

56. Xu J, Zhao S, Teng T, et al. Systematic comparison of two animal-tohuman transmitted human coronaviruses: SARS-CoV-2 and SARS-CoV. Viruses. 2020;12(2):244. doi:10.3390/v12020244

57. Shi J, Wen Z, Zhong G, et al. Susceptibility of ferrets, cats, dogs, and other domesticated animals to SARS-coronavirus 2. Science (New York, N.Y. 2020. doi:10.1126/science.abb7015

\section{Publish your work in this journal}

Infection and Drug Resistance is an international, peer-reviewed openaccess journal that focuses on the optimal treatment of infection (bacterial, fungal and viral) and the development and institution of preventive strategies to minimize the development and spread of resistance. The journal is specifically concerned with the epidemiology of antibiotic resistance and the mechanisms of resistance development and diffusion in both hospitals and the community. The manuscript management system is completely online and includes a very quick and fair peerreview system, which is all easy to use. Visit http://www.dovepress.com/ testimonials.php to read real quotes from published authors. 